\title{
Both epithelial cells and mesenchymal stem cell-derived chondrocytes contribute to the survival of tissue-engineered airway transplants in pigs
}

\author{
Tetsuhiko Go, MD, ${ }^{\mathrm{a}, *}$ Philipp Jungebluth, $\mathrm{MD},{ }^{\mathrm{a}, *}$ Silvia Baiguero, $\mathrm{PhD},{ }^{\mathrm{d}}$ Adelaide Asnaghi, $\mathrm{PhD},{ }^{\mathrm{e}}$ \\ Jaume Martorell, $\mathrm{PhD},{ }^{\mathrm{f}}$ Helmut Ostertag, $\mathrm{MD}, \mathrm{PhD},{ }^{\mathrm{g}}$ Sara Mantero, $\mathrm{PhD},{ }^{\mathrm{e}}$ Martin Birchall, MD, FRCS, ${ }^{\mathrm{h}}$ \\ Augustinus Bader, $\mathrm{PhD},{ }^{\mathrm{i}}$ and Paolo Macchiarini, $\mathrm{MD}, \mathrm{PhD}^{\mathrm{a}, \mathrm{b}, \mathrm{c}}$
}

Objective: We sought to determine the relative contributions of epithelial cells and mesenchymal stem cell-derived chondrocytes to the survival of tissue-engineered airway transplants in pigs.

\begin{abstract}
Methods: Nonimmunogenic tracheal matrices were obtained by using a detergent-enzymatic method. Major histocompatibility complex-unmatched animals (weighing $65 \pm 4 \mathrm{~kg}$ ) were divided into 4 groups $($ each $n=5$ ), and $6 \mathrm{~cm}$ of their tracheas were orthotopically replaced with decellularized matrix only (group I), decellularized matrix with autologous mesenchymal stem cell-derived chondrocytes externally (group II), decellularized matrix with autologous epithelial cells internally (group III), or decellularized matrix with both cell types (group IV). Autologous cells were recovered, cultured, and expanded. Mesenchymal stem cells were differentiated into chondrocytes by using growth factors. Both cell types were seeded simultaneously with a dual-chamber bioreactor. Animals were not immunosuppressed during the entire study. Biopsy specimens and blood samples were taken from recipients continuously, and animals were observed for a maximum of 60 days.
\end{abstract}

Results: Matrices were completely covered with both cell types within 72 hours. Survival of the pigs was significantly affected by group $(P<.05$; group I, $11 \pm 2$ days; group II, $29 \pm 4$ days; group III, $34 \pm 4$ days; and group IV, $60 \pm 1$ days). Cause of death was a combination of airway obstruction and infection (group I), mainly infection (group II), or primarily stenosis (group III). However, pigs in group IV were alive, with no signs of airway collapse or ischemia and healthy epithelium. There were no clinical, immunologic, or histologic signs of rejection despite the lack of immunosuppression.

Conclusions: We confirm the clinical potential of autologous cell- and tissue-engineered tracheal grafts, and suggest that the seeding of both epithelial and mesenchymal stem cell-derived chondrocytes is necessary for optimal graft survival. (J Thorac Cardiovasc Surg 2010;139:437-43)

Long-segment airway stenosis is life-threatening, but present surgical options are not ideal. ${ }^{1} \mathrm{~A}$ tracheal graft suitable for clinical use has to have the biomechanical properties of

\footnotetext{
From the Departments of General Thoracic Surgery, Hospital Clinic, ${ }^{\mathrm{a}}$ Institut d'Investigacions Biomèdiques August Pi i Sunyer (IDIBAPS), CIBER Enfermedades Respiratorias, ${ }^{\mathrm{b}}$ and Universitat de Barcelona, ${ }^{\mathrm{c}}$ Barcelona, Spain; Pharmaceutical Sciences, ${ }^{\mathrm{d}}$ University of Padua, Italy; Bioengineering, ${ }^{\mathrm{e}}$ Politecnico di Milano, Milano, Italy; Immunology, ${ }^{\mathrm{f}}$ Hospital Clinic, Barcelona, Spain; Pathology, ${ }^{\mathrm{g}}$ Klinikum Hannover, Hannover, Germany; University College of London Ear Institute, ${ }^{\mathrm{h}}$ London, United Kingdom; Cell Techniques and Applied Stem Cell Biology, ${ }^{\mathrm{i}}$ Center of Biotechnology and Biomedicine, University of Leipzig, Leipzig, Germany. Disclosures: None.

Read at the Eighty-ninth Annual Meeting of The American Association for Thoracic Surgery, Boston, Mass, May 9-13, 2009.

Supported by the Ministerio de Sanidad y Consumo, Instituto de Salud Carlos III, Fondo de Investigación Sanitaria (FIS; PI050987).

* Contributed equally to the work.

Received for publication May 10, 2009; revisions received Sept 14, 2009; accepted for publication Oct 4, 2009; available ahead of print Dec 6, 2009.

Address for reprints: Paolo Macchiarini, MD, PhD, Department of General Thoracic

Surgery, Hospital Clinic, University of Barcelona, Villarroel 170, E-08036 Barce-

lona, Spain (E-mail: pmacchia@ub.edu).

$0022-5223 / \$ 36.00$

Copyright (c) 2010 by The American Association for Thoracic Surgery

doi:10.1016/j.jtcvs.2009.10.002
}

flexibility, strength to avoid collapse, and formation of airtight seals. ${ }^{2,3}$ It should not excite a rejection response and promote cell adhesion and growth, including angiogenesis. Such an ideal construct has proved elusive and difficult to reproduce. ${ }^{4-7}$ We recently performed the world's first stem cell-based, fully tissue-engineered tracheal graft, which has been a success to date. ${ }^{8}$ However, before we used the graft in human subjects, we evaluated the relative contribution of the autologous biopsy-derived epithelial cells and mesenchymal stem cell (MSC)-derived chondrocytes for the survival of seeded decellularized scaffolds when implanting them orthotopically in pigs. Results are presented here.

\section{MATERIALS AND METHODS}

Thirty Yorkshire Duroc pigs (Isoquimen S/L, Barcelona, Spain) weighing $65 \pm 4 \mathrm{~kg}$ were used. All animals received care in compliance with the "Principles of laboratory animal care" formulated by the National Society for Medical Research and the "Guide for the care and use of laboratory animals" prepared by the Institute of Laboratory Animal Resources, National Research Council, and published by the National Academy Press, revised 1996. This study was approved by the Anima Care and Use Committee and the Bioethics Committee of the University of Barcelona. 


\author{
Abbreviations and Acronyms \\ $\mathrm{DM}=$ decellularized matrix \\ $\mathrm{MHC}=$ major histocompatibility complex \\ MSC $=$ mesenchymal stem cell \\ PBS $=$ phosphate-buffered saline
}

\begin{abstract}
Study Design
The entire trachea (median length, $12 \mathrm{~cm}$ ) was retrieved from 10 donors. Tracheal matrices were engineered according to our published method. ${ }^{8-10}$ Bone marrow-derived MSCs and mucosal epithelial cells were obtained from the intended recipients $(n=20)$ by means of bone marrow aspiration followed by expansion and differentiation, as previously described, bronchial biopsy, respectively. ${ }^{8}$ Recipients were randomly (computer-generated code) divided into 4 groups of 5 animals, and $6 \mathrm{~cm}$ of their tracheas was replaced with decellularized matrix (DM) only (group I); DM with external, autologous MSC-derived chondrocytes (group II); DM with internal, autologous epithelial cells (group III); or DM seeded with both cell types (group IV). Biopsy specimens and blood samples were continuously taken from recipients, and animals were observed for a maximum of 60 days. Tracheas were harvested and evaluated postmortem.
\end{abstract}

\section{Anesthesia: Tracheal Harvesting From Donors and Autologous Cell Isolation From Recipients}

Animals $(\mathrm{n}=10)$ were premedicated with azaperone $(4 \mathrm{mg} / \mathrm{kg}$ administered intramuscularly; Esteve S.A., Barcelona, Spain) and intravenous thiopental injection (10 mg/kg; B. Braun Medical S.A., Rubi, Barcelona, Spain) and relaxed with intravenous vecuronium (Norcuron; $6 \mathrm{mg} \cdot \mathrm{kg}^{-1} \cdot \mathrm{h}^{-1}$; Organon S.A., Barcelona, Spain). Orotracheal intubation was obtained with a $7.5 \mathrm{~F}$ or $8 \mathrm{~F}$ endotracheal tube. Anesthesia was maintained with fentanyl $\left(1 \mu \mathrm{g} \cdot \mathrm{kg}^{-1} \cdot \mathrm{h}^{-1}\right.$, B. Braun Medical S.A.) and propofol $\left(3-5 \mathrm{mg} \cdot \mathrm{kg}^{-1}\right.$. $\mathrm{h}^{-1}$, B. Braun Medical S.A.) intravenous infusions. A pulse oximeter (BCI, Inc, Waukesha, Wis) placed at the pig's tail was used to measure the arterial oxygen saturation. For retrieval, a median cervicosternotomy was performed to dissect the trachea in its entirety. ${ }^{7,8,10}$ Thereafter, animals were killed with an intravenous bolus of fentanyl, propofol, and potassium chloride $(40 \mathrm{mEq}$; B. Braun, Melsungen, Germany). The entire tracheas were taken $(12 \mathrm{~cm})$ and then divided into 2 parts of $6 \mathrm{~cm}$ each and stored in a stock solution made of phosphate-buffered saline (PBS; Invitrogen S.A., Barcelona, Spain) containing $1 \%$ antibiotic and antimycotic solution (Sigma Chemical Co, Barcelona, Spain). Future graft recipients were anesthetized similarly. Cell populations were obtained by means of a single $80-\mathrm{mL}$ aspiration of bone marrow from the crista iliaca and tracheal endoscopic epithelial biopsy specimens, and maximal attention was paid to isolate cells under completely sterile conditions to avoid cell-culture contamination. After sample harvesting, weaning was induced, and animals were extubated, with time to recover.

\section{Matrix Bioengineering}

Matrix bioengineering followed our previously published method. ${ }^{8-10}$ Briefly, tracheas were incubated with multiple treatment cycles, including Aqua milliQ (Millipore, Madrid, Spain) storage for 48 hours at $4^{\circ} \mathrm{C}$, and then incubated in 4\% sodium deoxycholate and $2000 \mathrm{kU}$ DNase-I (Sigma Chemical Co), respectively, for 3 hours. After 17 cycles, which was the previously determined optimum point for loss of antigenicity but preservation of biomechanical strength, ${ }^{10}$ samples were examined to check for the absence of intact cells and major histocompatibility complex (MHC) expression. Finally, tracheas were then stored in PBS at $4^{\circ} \mathrm{C}$ until use.

\section{Autologous Cell Isolation and Culture}

MSCs were isolated by purifying the aspirated bone marrow through a previously prepared Percoll (Sigma Chemical Co) gradient (1:9 Percoll/
$\mathrm{NaCl}$ ). Bone marrow was centrifuged at $500 \mathrm{~g}$ (relative centrifugal force) at $4^{\circ} \mathrm{C}$, and the thin, bright cell layer was gently removed. Counted cells were seeded at a density of $1.1 \times 10^{6} / \mathrm{mL}$ with complete medium (Dulbecco's modified Eagle's medium containing 1000 mg L-glucose, Sigma-Aldrich), $10 \%$ fetal bovine serum (Biological Industries, Beit Haemek, Israel), 100 $\mathrm{U} / \mathrm{mL}$ penicillin, $100 \mu \mathrm{g} / \mathrm{mL}$ streptomycin, and $2 \mathrm{mmol} / \mathrm{L}$ GlutaMax-I (Invitrogen) with $5 \mathrm{ng} / \mathrm{mL}$ basic fibroblast growth factor (PeproTech, London, United Kingdom). Cells were used for differentiation, reaching 3 to 4 passages. According to a standard cell-culture protocol, differentiation was induced by adding $10 \mathrm{ng} / \mathrm{mL}$ recombinant human transforming growth factor $\beta 3$ (R\&D Systems, Abingdon, United Kingdom), $10 \mathrm{nmol} / \mathrm{L}$ recombinant parathyroid-related peptide (PeproTech), $100 \mathrm{nmol} / \mathrm{L}$ dexamethasone, and $10 \mathrm{mg} / \mathrm{mL}$ insulin (both Sigma-Aldrich) and incubating for 72 hours. There were no fibroblasts detected before seeding the tracheal matrix.

Epithelial biopsy specimens were incubated with $0.25 \%$ trypsin-ethylenediamine tetraacetic acid (Gibco, Prat de Llobregat, Spain) overnight at $4^{\circ} \mathrm{C}$ and the next morning for 45 minutes at $37^{\circ} \mathrm{C}$. The mixture was then neutralized with complete medium (containing fetal bovine serum), and the liquid was removed and transferred to a new tube. Thereafter, liquid was centrifuged at $1000 \mathrm{rpm}$ for 10 minutes, supernatant was removed, and the pellet was resuspended. Obtained cells were then transferred to small flasks and cultured with a specific airway epithelial cell growth medium (PromoCell; Lab S.A., Barcelona, Spain) containing $13 \mathrm{mg} / 1 \mathrm{~mL}$ bovine pituitary extract, $5.0 \mu \mathrm{g} / 500 \mu \mathrm{L}$ human recombinant epidermal growth factor, $250.0 \mu \mathrm{g} / 500$ $\mu \mathrm{L}$ epinephrine, $250.0 \mu \mathrm{g} / 500 \mu \mathrm{L}$ hydrocortisone, $2.5 \mathrm{mg} / 500 \mu \mathrm{L}$ recombinant human insulin, $50.0 \mathrm{ng} / 500 \mu \mathrm{L}$ retinoic acid, $5.0 \mathrm{mg} / 500 \mu \mathrm{L}$ transferrin, and $3.35 \mu \mathrm{g} / 500 \mu \mathrm{L}$ tri-iodo-L-thyronine in $500 \mathrm{~mL}$. The cell culture was performed according to a standard protocol. However, Hanks buffered salt solution (Sigma) was used when removing cells. Cells were used for seeding at the point at which they reached 4 to 5 passages. Both cell lines were separately seeded on the pre-engineered matrices by using a dedicated, dualchamber bioreactor. The device provided continuous rotation of the graft, exposing cells to a covering film of alternating gas and liquid phases.

\section{Histology and Immunochemistry}

Tracheas were analyzed before transplantation and after harvesting. Samples were washed thoroughly in saline before use. To quantify the remaining cells after each cycle of the detergent-enzymatic method treatment, we analyzed tissues according to our protocol. Briefly, nuclei were visualized with 4'-6-diamidino-2-phenylindole (Vector Laboratories, Inc, Burlingame, Calif), and cell density was determined. Paraffin-embedded tissue sections measuring $5 \mu \mathrm{m}$ were mounted on slides and stained with hematoxylin and eosin (Merck, Darmstadt, Germany) to evaluate morphologic changes. The presence of MHC markers was evaluated by means of immunostaining with monoclonal anti-MHC class I OX27 and anti-MHC class II OX4 antibodies (Abcam, Cambridge, United Kingdom).

\section{Physical Strain Tests}

Bioengineered matrices from each group were tested by using a previously published method ${ }^{10}$ based on a tensile-test device (Zwick/Roell, version Z0.5TS; Barcelona, Spain). Each sample was subjected to increasing uniaxial tensile testing until rupture, which was confirmed by the loss of load and the appearance of tears in the tissue. The specimens were clamped into sample holders, a preload (preliminary force) of $2 \mathrm{~N}$ was applied, and the trial was started at a constant elongation rate of $1 \mathrm{~mm} / \mathrm{s}$ at room temperature. The tensile tester recorded the load and elongation to which the tissue was subjected in real time.

\section{Orthotopic Graft Transplantation and Postoperative Observation}

The graft transplantation was performed according to our previously described method. ${ }^{6,711}$ Briefly, after general anesthesia was achieved, recipients' tracheas were exposed through an anterior midline cervical incision. 


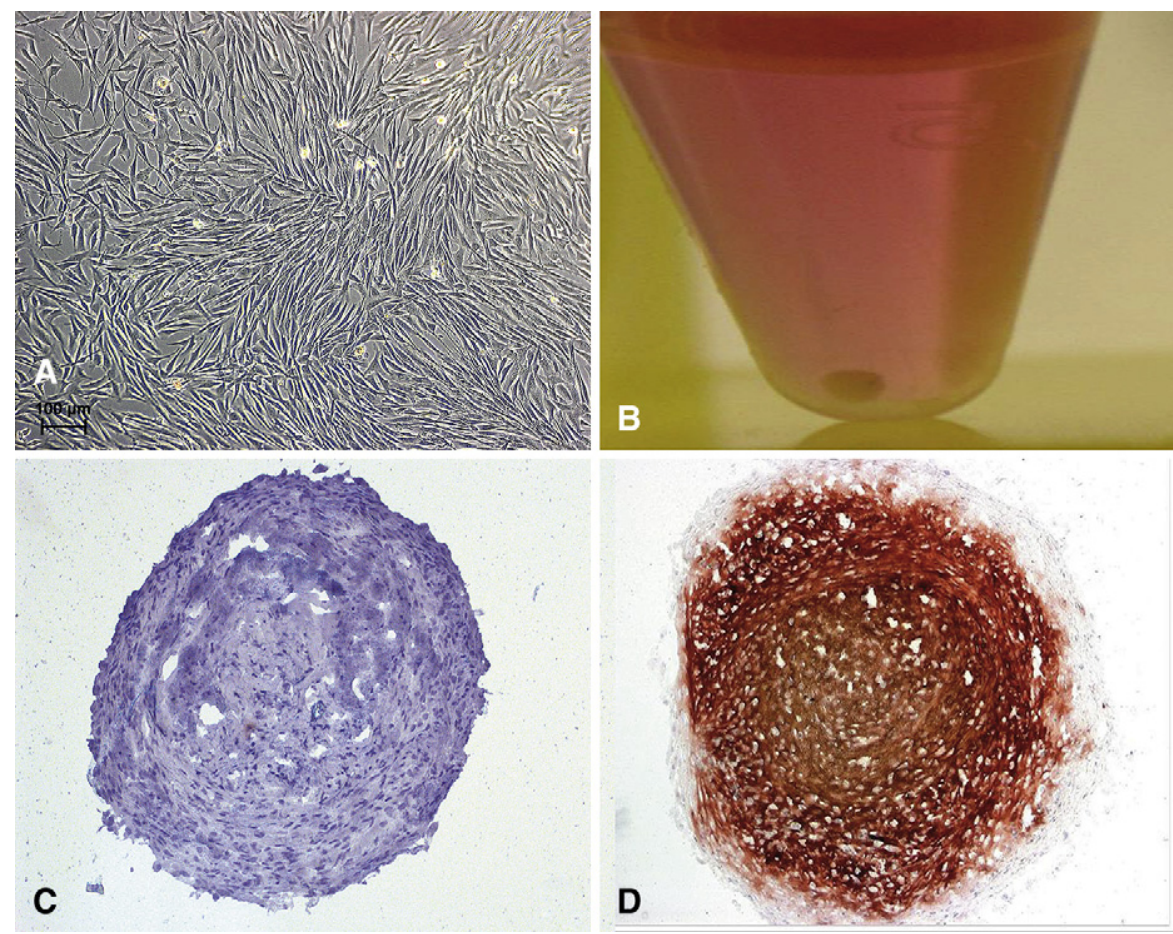

FIGURE 1. A, Mesenchymal stem cells in vitro cultured after isolating with Percoll from bone marrow aspirate. B, Mesenchymal stem cell pellet after centrifugation at $1000 \mathrm{rpm}$ for 5 minutes. Standard method for chondrocyte differentiation: culture cells with $10 \mathrm{ng} / \mathrm{mL}$ recombinant human transforming growth factor $\beta 3$. C, Immunohistostaining of mesenchymal stem cells not treated with $10 \mathrm{ng} / \mathrm{mL}$ transforming growth factor $\beta 3$ as a negative control. No collagen type II was detected. D, Immunohistostaining for collagen type II detected after 21 days with transforming growth factor $\beta 3$.

Then the sternohyoid muscles were divided and the cervical fat lobe was dissected. We opened the pretracheal fascia, mobilized the intrathoracic trachea, and placed traction sutures to retract it superiorly. The endotracheal tube was pulled back into the subglottic larynx, and 10 to 12 tracheal rings $(6 \mathrm{~cm})$ of the recipients' cervical tracheas were excised and replaced with the tissue-engineered graft. At least 2 tracheal rings below the cricoid were left in place to anastomose the tracheal graft. The anastomoses were made with a 4-0 continuous polydiaxone (Ethicon, Inc, Somerville, $\mathrm{NJ}$ ) parachute sutures of the posterior membranous wall and 5-0 absorbable polygalactin (Vicryl; Ethicon, Inc) interrupted sutures on the anterolateral anastomosis, with knots tied extraluminally. Gas exchange during performance of the anastomoses was through apneic hyperoxygenation. The skin was closed in the usual fashion. Postoperatively, antibiotics (cefazolin, $2 \mathrm{~g} / \mathrm{d}$ administered intravenously; Lilly, Madrid, Spain) and analgesics (Enantyum [dexketoprofen], $40 \mathrm{mg} / 12 \mathrm{~h}$; Menarini, Barcelona, Spain) were administered intravenously for the first 7 days. Animals were placed in cages and fed standard laboratory pig food and water ad libitum. They were examined daily for 60 days or until death, if earlier, for clinical signs of inflammation or rejection and for general health. Blood samples were taken weekly to check for the development of antibodies and increased inflammatory response. The presence of bacteria and fungi before and after implantation was determined by means of conventional microbiologic techniques performed on small, fresh tissue biopsy specimens.

\section{Analysis of Tissue From Pig Recipients}

Samples were formalin fixed and paraffin embedded before staining with hematoxylin and eosin (Merck). Anti-swine leukocyte antigen antibodies were tested at $7,15,23$, and 30 days after matrix implantation by using a modification of the standard flow cytometric crossmatch on lymph node cells, as previously described. ${ }^{10}$ Briefly, donor pig lymph node cells were incubated for 30 minutes with recipient serum and rinsed 3 times in PBS, and a fluorescein-marked anti-porcine immunoglobulin and phycoerythrin-marked anti-porcine CD3 was added for 30 minutes. A FACS scan (FACS Aria; Becton-Dickinson, Erembodegem, Belgium) was used to evaluate the double fluorescence. The coefficient between the mean channel in test serum in negative control serum for $\mathrm{T}$ cells (defined by mentioned double fluorescence) was recorded. We considered a ratio of greater than 2.9 to be positive based on previous samples obtained before implantation. Immunochemistry was performed with a rabbit anti-CD3 antibody (Dako, Glostrup, Denmark) and mouse anti-L1 antibody (Dako), respectively, to identify $\mathrm{T}$ lymphocytes, monocytes/macrophages, and polymorphonuclear granulocytes.

\section{Statistical Analysis}

Continuous variables were compared by using the independent-samples $t$ test. The odds ratio was calculated to perform comparisons of categorical variables in between groups. Results are presented as the mean \pm standard deviation of the mean. SPSS software was used (version 12.0; SPSS, Inc, Chicago, Ill). Statistical significance was accepted at the 5\% level.

\section{RESULTS}

All bioengineered matrices were negatively stained for both MHC I and II. MSCs could be isolated from bone marrow aspiration and differentiated into chondrocytes (Figure 1). Epithelial cells were easily obtained by means of tracheal biopsy followed by cell culture (Figure 2, A and $B$ ). The bioengineered matrices were seeded through the bioreactor (Figure 2,D) to near confluence by 72 hours (Figure 3). There was no evidence of contamination on 

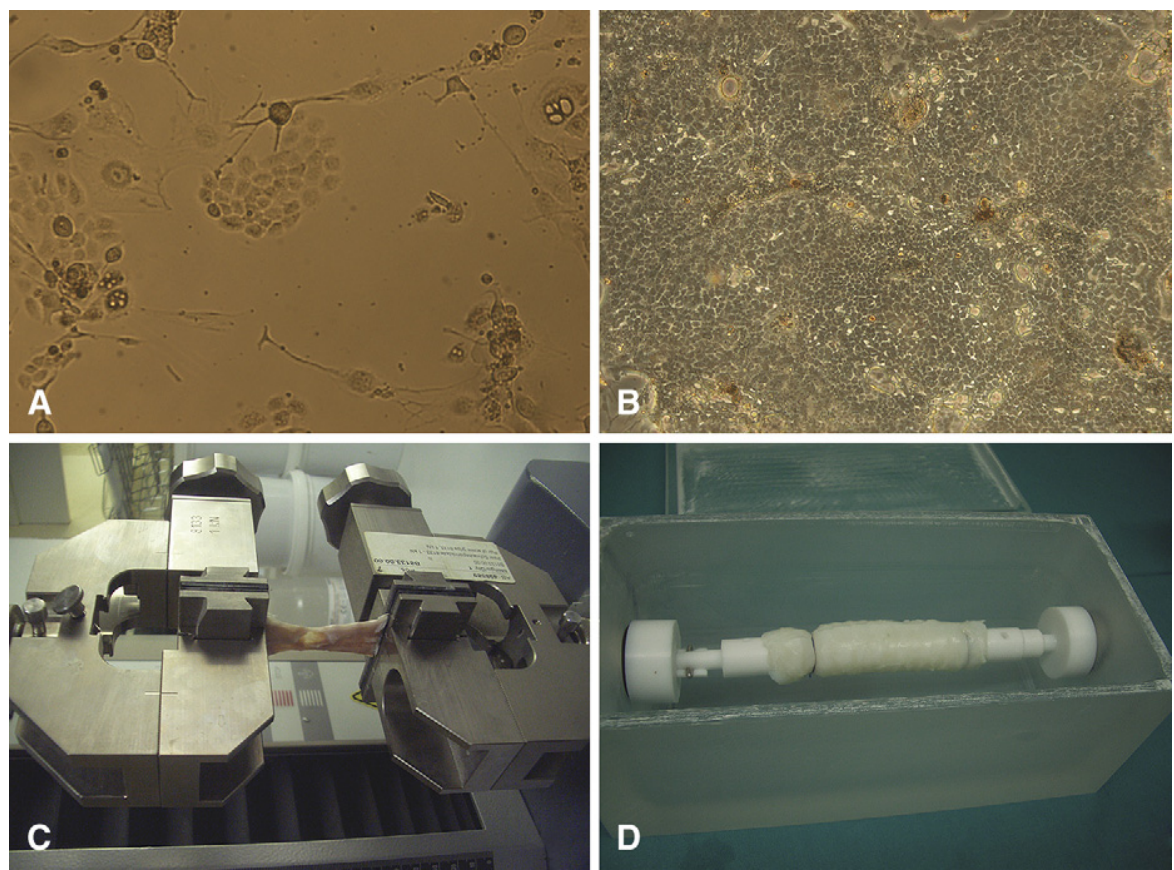

FIGURE 2. A, Epithelial in vitro cell culture after 3 days. B. Epithelial in vitro cell culture after 14 days. C, Tensile-test device evaluating the bioengineered graft. D, Engineered matrix fixed to the bioreactor before starting the seeding process.

bacteriologic analysis before implantation. Over the study period, the implanted graft did not elicit any rejection response, such as swine leukocyte antigen, and this was without immunosuppression. Orthotopically transplanted nonseeded matrices (group I) led to high-grade stenosis $(50 \%-75 \%$ decrease in diameter) and bacterium/funguscontaminated inner surface. The external seeding of MSCderived chondrocytes (group II) resulted in a quite stable
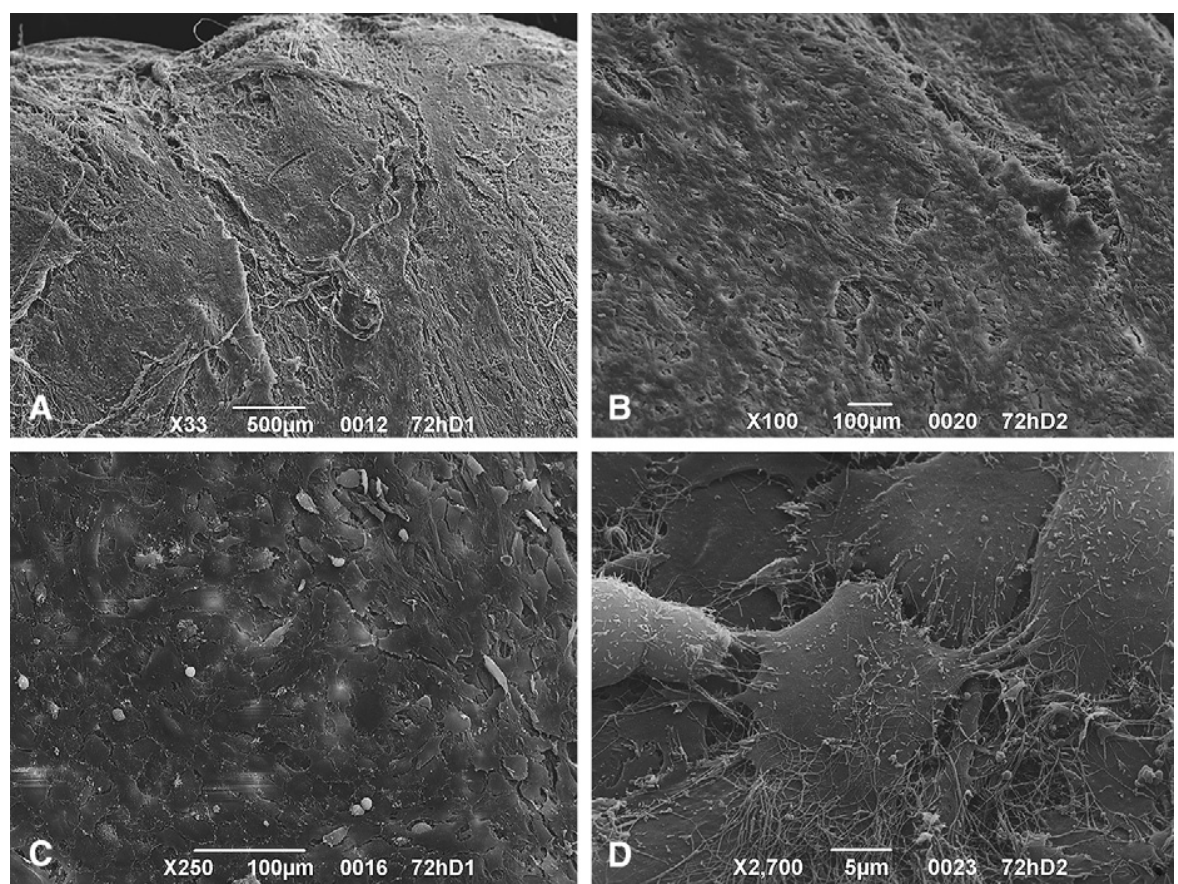

FIGURE 3. Scanning electron microscopic images at different amplifications showing seeded matrices (after 72 hours of seeding time). Different amplifications are shown. 


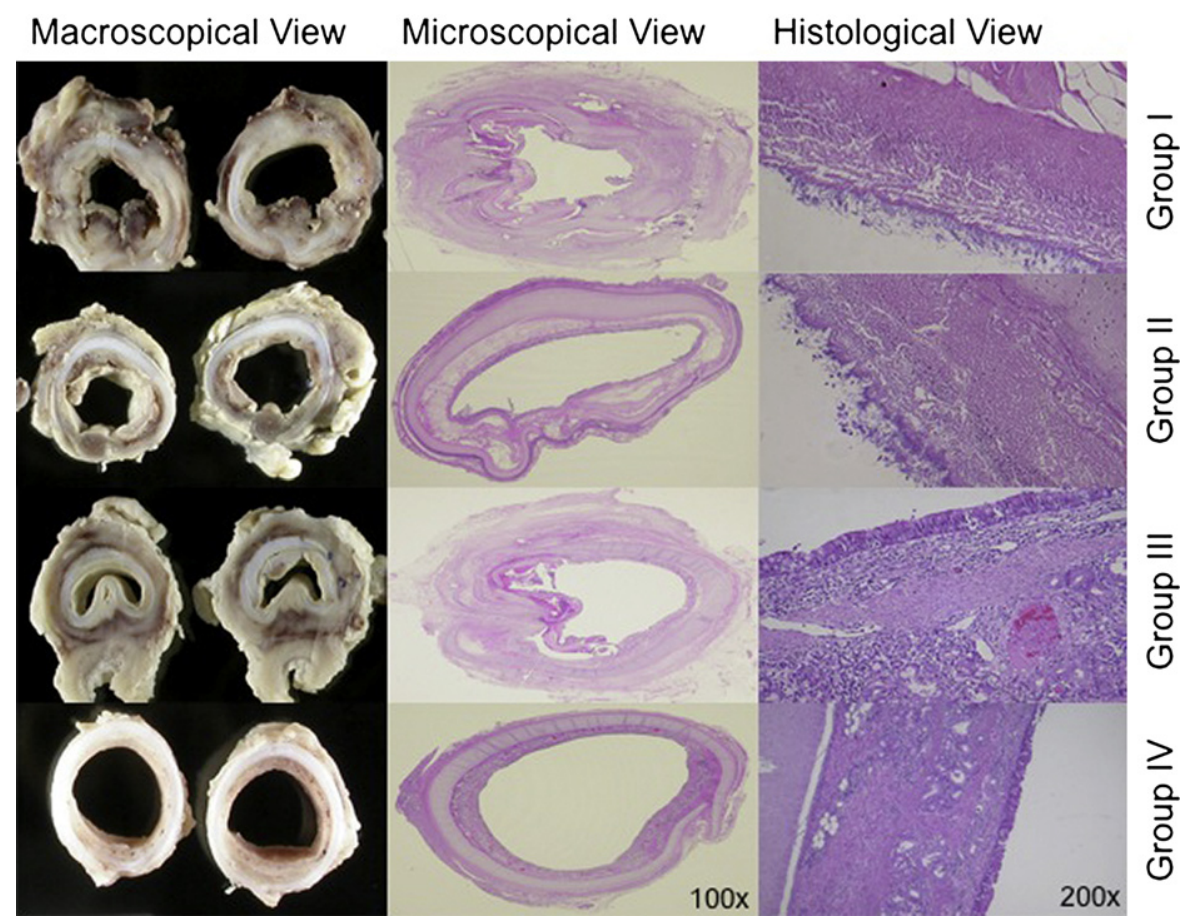

FIGURE 4. The first column shows formalin-embedded macroscopic views (transversal sections, group specific). The second (100×) and third (200×) columns display a microscopic view of hematoxylin and eosin histologic transversal sections (group specific). For group I (decellularized matrix only), both stenosis and the inflammatory process are visible. For group II (decellularized matrix with external, autologous mesenchymal stem cell-derived chondrocytes), less stenosis but a high grade of bacterial/fungal contamination is shown. For group III (decellularized matrix with internal, autologous epithelial cells), less inflammatory signs and no bacterial/fungal contamination are shown (high stenosis caused by weakness). For group IV (decellularized matrix with both cell types), no stenosis or contamination is shown.

( $25 \%-50 \%$ decrease in diameter) but highly contaminated graft. Grafts seeded only with epithelial cells on the inner surface (group III) also showed high-grade stenosis $(>75 \%)$, apparently caused by malacia but without bacterial/fungal contamination. Only seeding both sides of the matrices resulted in a healthy functional graft $(<25 \%$ decrease in diameter, Figure 4), and only slight postoperative inflammatory signs were detected. The histologic and macroscopic findings correlated with the animals' clinical outcome. With respect to the time point of the pigs' death, only group IV animals remained healthy enough to avoid death before the 60-day censor point. All other animals were killed significantly earlier because of signs of marked respiratory distress not amenable to simple treatment measures (group I, $11 \pm 2$ days; group II, $29 \pm 4$ days; and group III, $34 \pm 4$ days). Preimplantation strain tests (Figure 2, $C$ ) showed no significant difference between the graft and the native trachea, as demonstrated before. ${ }^{10}$ However, postoperatively retrieved grafts from groups I to III, but not group IV, showed a statistically lower resilience (Table 1).

\section{DISCUSSION}

Our recent first in a human subject experience with a reseeded, decellularized tracheal graft $^{8}$ was based on the findings described here. This experimental study explored the biologic mechanisms underlying the success of the

TABLE 1. Comparison of the mechanical characteristics of native and bioengineered tracheas (retrieved postmortem)

\begin{tabular}{|c|c|c|c|c|c|}
\hline \multirow[b]{2}{*}{ Characteristics } & \multirow[b]{2}{*}{ Native trachea } & \multicolumn{4}{|c|}{ Bioengineered grafts (postmortem), groups } \\
\hline & & $\mathbf{I}$ & II & III & IV \\
\hline \multicolumn{6}{|l|}{ Mechanical } \\
\hline Maximum force $(\mathrm{N})$ & $182.0 \pm 5.1$ & $58.1 \pm 8.8^{*}$ & $87.5 \pm 6.6^{*}$ & $60.4 \pm 8.7^{*}$ & $174.8 \pm 7.7 \dagger$ \\
\hline Rupture force $(\mathrm{N})$ & $58.3 \pm 2.9$ & $24.4 \pm 4.7 *$ & $32.7 \pm 3.7 *$ & $24.2 \pm 5.2^{*}$ & $55.6 \pm 2.6 \dagger$ \\
\hline Tracheal rupture point $(\mathrm{cm})$ & $12.1 \pm 0.4$ & $7.3 \pm 0.4^{*}$ & $7.9 \pm 0.3 *$ & $7.9 \pm 0.9^{*}$ & $11.9 \pm 0.4 \dagger$ \\
\hline Tissue deformation $(\%)$ & $202 \pm 7$ & $121 \pm 7 *$ & $132 \pm 5^{*}$ & $132 \pm 14^{*}$ & $198 \pm 7 \dagger$ \\
\hline
\end{tabular}


transplanted tissue-engineered graft. The first question we wished to answer was as follows: What is the relative contribution of the 2 cell types seeded onto the scaffold, and were both cell types necessary for graft and recipient survival? The study confirmed the applicability of the decellularization, cell preparation, and reseeding techniques, as well as the ease of application of our tracheal bioreactor. However, attention should be paid during cell isolation and culture to avoid contamination caused by fibrocyte proliferation. Notably, no animal demonstrated the development of local or systemic rejection responses to any residual donor antigens, and this was without the administration of immunosuppressive medication. Zani and colleagues ${ }^{12}$ demonstrated in 2008 the potential of tissue healing and functional restoration if epithelial and endothelial cells are present at the same time, even with a lack of an ordered architectural relationship. In our model these effects might be provided by residual MSCs in the MSC-derived chondrocyte culture, inducing rapid angiogenesis and making the graft viable. As Genden and associates ${ }^{13}$ showed in 2003 , the necessity of re-epithelialization is highly important for graft integrity and for protection against a fibroproliferative response of the recipient. Additionally, we showed that long-segment grafts need to be seeded with epithelial cells before orthotopic transplantation to avoid bacterial/fungal contamination. Compared with our previous technically demanding method of direct graft revascularization, ${ }^{6}$ the approach described here makes the tracheal reconstruction much more practicable and reproducible but nevertheless with an outstanding outcome.

Gathering knowledge and information regarding the strain abilities of a tracheal graft were disappointing. ${ }^{14,15}$ Only a few publications were helpful when designing the tensile test; however, in vitro and in vivo findings did not correlate with each other. Our strain tests showed no difference in biomechanical properties between decellularized scaffolds before implantation, scaffolds seeded with both cell types 60 days after implantation, and normal trachea. Therefore one can assume that there would be no collapse of such grafts. However, our tensile-testing device provided only longitudinal forces, and therefore the true test followed in vivo, when multidirectional forces were applied. Under these conditions, grafts with no cells or only 1 cell type failed to retain functional strength, leading to incompetent airways.

In conclusion, this experimental study demonstrated for the first time the necessity of both MSC-derived chondrocytes and epithelial cells to obtain a functional and proper long-segment tracheal graft with clinical effect. These findings and the applied method of tissue engineering will help forward the reconstruction of the trachea in human subjects. Further studies are required to elucidate the angiogenesis mechanisms and interactions between residual MSCs.

\section{References}

1. Grillo HC. Tracheal replacement: a critical review. Ann Thorac Surg. 2002;73: 1995-2004.

2. Macchiarini P. Trachea-guided generation: déjà vu all over again? J Thorac Cardiovasc Surg. 2004;128:14-6.

3. Birchall M, Macchiarini P. Airway transplantation: a debate worth having? Transplantation. 2008;85:1075-80.

4. Macchiarini P, Walles T, Biancosino C, Mertsching H. First human transplantation of a bioengineered airway tissue. J Thorac Cardiovasc Surg. 2004;128:638-41.

5. Sekine T, Nakamura T, Matsumoto K, Liu Y, Ueda H, Tamura N, et al. Carinal reconstruction with a Y-shaped collagen-conjugated prosthesis. J Thorac Cardiovasc Surg. 2000;119:1162-8.

6. Macchiarini P, Lenot B, de Montpréville VT, Dulmet E, Mazmanian GM, Fattal M, et al. Heterotopic pig model for direct revascularization and venous drainage of tracheal allografts. Paris-Sud University Lung Transplantation Group. J Thorac Cardiovasc Surg. 1994;108:1066-75.

7. Macchiarini P, Mazmanian GM, de Montpréville VT, Dulmet E, Fattal M, Lenot B, et al. Experimental tracheal and tracheoesophageal allotransplantation. Paris-Sud University Lung Transplantation Group. J Thorac Cardiovasc Surg. 1995; 110:1037-46.

8. Macchiarini P, Jungebluth P, Go T, Asnaghi MA, Rees LE, Cogan TA, et al. Clinical transplantation of a tissue-engineered airway. Lancet. 2008;372:2023-30.

9. Conconi MT, De Coppi P, Di Liddo R, Vigolo S, Zanon GF, Parnigotto PP, et al. Tracheal matrices, obtained by a detergent-enzymatic method, support in vitro the adhesion of chondrocytes and tracheal epithelial cells. Transpl Int. 2005;18:727-34.

10. Jungebluth P, Go T, Asnaghi A, Bellini S, Martorell J, Calore C, et al. Structural and morphological evaluation of a novel detergent-enzymatic tissue engineered tracheal tubular matrix. J Thorac Cardiovasc Surg. 2009;138:586-93.

11. Macchiarini P, Dulmet E, de Montpreville V, Mazmanian GM, Chapelier A, Dartevelle P. Tracheal growth after slide tracheoplasty. J Thorac Cardiovasc Surg. 1997;113:558-66.

12. Zani BG, Kojima K, Vacanti CA, Edelman ER. Tissue-engineered endothelial and epithelial implants differentially and synergistically regulate airway repair. Proc Natl Acad Sci U S A. 2008;105:7046-51.

13. Genden EM, Iskander A, Bromberg JS, Mayer L. The kinetics and pattern of tracheal allograft re-epithelialization. Am J Respir Cell Mol Biol. 2003;28:673-81.

14. Behrend M, Kluge E, Von Wasielewski R, Klempnauer J. The mechanical influence of tissue engineering techniques on tracheal strength: an experimental study on sheep trachea. J Invest Surg. 2002;15:227-36.

15. Behrend M, Kluge E, Schüttler W, Klempnauer J. The mechanical stability under load of tracheal anastomoses after various phases in vivo. Laryngoscope. 2002; 112:364-9.

\section{Discussion}

Dr Yolonda Colson (Boston, Mass). I have no conflicts.

You are to be congratulated on doing an amazing job in getting this to actually work, and I think that you have defined a very nice clinical problem that currently does not have a great solution. Having said that, I think there are a lot of obvious questions in terms of longer-term follow-up and analysis. I have several questions.

You have 4 different groups that fail for different reasons, except group 4, which does well. Were those groups done sequentially, meaning did you do all the animals in group 1, all the animals in group 2, and so, on so that there is a learning curve in terms of infection and how you do it, or were they randomized?

Dr Go. Yes, it was randomized.

Dr Colson. Therefore there were some in the different groups done after your success in group 4 ?

Dr Go. Exactly.

Dr Colson. I read the article that you have submitted, and you also talk about there being no evidence of rejection or reaction. What was done to actually know that other than grossly looking at it because you did a lot of biopsies and obtained a lot of blood 
samples in the article that you did not talk about here. Second, the animals in group 4 were all killed at 60 days, which is a little less than 1 month after group 3. Is 60 days significant? In terms of longer-term follow-up, does that help us clinically?

Dr Go. To answer the first question, we took blood samples for analysis, as I mentioned in the presentation, to determine, for example, swine leukocyte antigen and other information and the C-reactive protein level. As for the rejection, I just mentioned the swine leukocyte antigen.

Excuse me, what was the second question?

Dr Colson. The animals in group 4 were killed at 60 days routinely rather than seeing what their long-term

Dr Go. To my knowledge, 1 month in the pig is comparable with 6 months in a human subject, which means 60 days in a pig translates to 360 days in a human subject. However, this is just follow-up for the middle term. I would not say this is for the long-term result.
Dr Colson. Have you seen that in your patient whose case was published in Lancet?

Dr Go. Yes. Actually, after 3 months of follow-up, she is doing fine.

Dr Frank C. Detterbeck (New Haven, Conn). You replaced a 6-cm segment of trachea?

Dr Go. Yes.

Dr Detterbeck. Tell me about the respiratory endothelium. It seems like that has been the problem with longer-segment tracheal replacement. Unless I missed it, you were seeding with chondrocytes primarily, right?

Dr Go. Sorry, I did not hear the question.

Dr Detterbeck. You seeded your bioengineered grafts with chondrocytes.

Dr Colson. On the outside and epithelium on the inside.

Dr Detterbeck. Epithelium on the inside. Okay. I missed that part. Thank you. 